\title{
Antecedents of Condom-Protected Oral Sex Among Young Black MSM
}

\author{
Richard A. Crosby PhD, Robin R. Milhausen PhD, Cynthia A. Graham PhD, \\ William L. Yarber HSD, Stephanie A. Sanders PhD, Angelica Geter DrPH \& \\ Leandro Mena MD
}

To cite this article: Richard A. Crosby PhD, Robin R. Milhausen PhD, Cynthia A. Graham PhD, William L. Yarber HSD, Stephanie A. Sanders PhD, Angelica Geter DrPH \& Leandro Mena MD (2017): Antecedents of Condom-Protected Oral Sex Among Young Black MSM, International Journal of Sexual Health, DOI: 10.1080/19317611.2017.1292339

To link to this article: http://dx.doi.org/10.1080/19317611.2017.1292339

Accepted author version posted online: 15 Feb 2017.

Submit your article to this journal 지

Џ Article views: 7

Q View related articles $\square$

View Crossmark data ¿ 


\section{ACCEPTED MANUSCRIPT}

\section{Antecedents of Condom-Protected Oral Sex Among Young Black MSM}

Richard A. Crosby, PhD, ${ }^{1,2,3}$ Robin R. Milhausen, $\mathrm{PhD},{ }^{2,3,4}$ Cynthia A. Graham, $\mathrm{PhD},{ }^{2,3,5}$ William L. Yarber, HSD ${ }^{2,3,6,7}$ Stephanie A. Sanders, $\mathrm{PhD},{ }^{2,3,7}$, Angelica Geter, $\mathrm{DrPH},{ }^{1}$ Leandro Mena, $\mathrm{MD}^{8}$

${ }^{1}$ Department of Health Behavior, College of Public Health, University of Kentucky, Lexington, KY, 40506

${ }^{2}$ Rural Center for AIDS/STD Prevention, Indiana University, Bloomington, IN 47405 USA

${ }^{3}$ The Kinsey Institute for Research in Sex, Gender, and Reproduction, Morrison Hall 313, Indiana University, Bloomington, IN 47405 USA

${ }^{4}$ Department of Family Relations and Applied Nutrition, University of Guelph, Guelph, N1H 5R1 Canada

${ }^{5}$ Department of Psychology, University of Southampton UK SO17 1BJ

${ }^{6}$ Department of Applied Health Science, Indiana University, Bloomington, IN, 47405 USA

${ }^{7}$ Department of Gender Studies, Memorial Hall E130, Indiana University, Bloomington, IN 47405 USA

${ }^{8}$ University of Mississippi Medical Center, Jackson, MS, 39216, USA 


\section{ACCEPTED MANUSCRIPT}

Correspondence: Richard Crosby, PhD, College of Public Health, 151 Washington Ave.

Lexington, KY 40506-0003; telephone: 5023705028 /FAX: 859-323-2933/e-mail:

crosbyr3@gmail.com

\section{Abstract}

Oral sex among men who have sex with men is a common mode of STI transmission. This study identified the prevalence and antecedents of condom-protected oral sex among a sample of 526 young Black MSM having oral sex in the past 90 days. Men engaging in condomless anal receptive sex were less likely to report always using condoms for oral $\operatorname{sex}(P=.007)$. Men agreeing that "condoms help me have better sex" $(P=.004)$ and those indicating always discussing condom use before sex were more likely to always use condoms for oral sex $(P=$ .002). These identified antecedents may inform behavioral intervention efforts.

Keywords

HIV Prevention; Men's sexual health; Pleasure; gay men 


\section{ACCEPTED MANUSCRIPT}

\section{Introduction}

Representing only $2 \%$ of the U.S. population, men who have sex with men (MSM) are disproportionately affected by the HIV/AIDS epidemic. ${ }^{1}$ Unfortunately, MSM --particularly those who are Black -- also bear a disproportionate burden of orally-acquired infections, including human Papillomavirus (HPV), Chlamydia, and gonorrhea. ${ }^{2}$ Although the odds of transmitting HIV through oral sex are extremely low, ${ }^{3}$ these estimates are based on the assumption that active cases of pharyngeal Chlamydia and gonorrhea are not present. Further, oral sex among MSM has been implicated in syphilis outbreaks in Brighton and Manchester, United Kingdom (accounting for $1 / 3$ of transmissions) and in Chicago, IL (USA) (accounting for $20 \%$ of cases of primary and secondary cases of syphilis between 1998 and 2002). ${ }^{4}$ Indeed, there is increasing concern about oral sex among MSM. ${ }^{5}$ Unfortunately, very little is known about correlates of condom use for oral sex among this population. ${ }^{6}$

Investigations specifically directed toward estimating the percent of MSM who use condoms consistently for oral sex are sparse and suggest limited behavioral uptake. For instance, consistent condom use during oral sex was reported among 1.3\% of MSM recruited from a community clinic in Malaysia. ${ }^{7}$ Condom use at last oral sex was reported among $9.1 \%$ of MSM recruited online in China. ${ }^{8}$ In a sample of 741 gay men in New York, less than 15\% reported consistent condom use during oral sex. ${ }^{9}$ In a study of 139 MSM between the ages of 25 and 30, $65 \%$ reported never using condoms for oral sex with regular or main partners over the past three months. One-half (50.4\%) reported never using condoms for oral sex with occasional partners. On average, participants did not intend to use condoms for oral sex. Only $25.3 \%$ had strong 


\section{ACCEPTED MANUSCRIPT}

intentions to always use condoms for oral sex with regular partners; $35.4 \%$ had strong intentions to use condoms for oral sex with occasional partners. ${ }^{6}$

Because risk of HIV transmission for HIV is much lower through oral sex than through anal or vaginal sex, individuals may engage in unprotected oral sex in place of higher risk behaviors. ${ }^{10}$ Limited research on the topic suggests the majority of MSM do not use condoms for oral sex most of the time,${ }^{6-9}$ putting themselves and their partners at risk for HIV and other sexually transmissible infections. Accordingly, the purpose of this study was to identify the prevalence and antecedents of condom-protected oral sex among a population of young Black MSM (YBMSM) residing in a city experiencing extremely high rates of pharyngeal Chlamydia, pharyngeal gonorrhea, and HIV incidence.

\section{Methods}

Study Sample

A convenience sample of 609 YBMSM was recruited for participation from a larger NIH-funded randomized controlled trial of a safer sex intervention program. Only baseline data (collected before randomization and intervention) was used for the present study. Recruitment occurred in a United States federally supported clinic designated specifically for the diagnosis and treatment of HIV and other sexually transmitted infections. The clinic was located in a midsize southern city. Inclusion criteria were: 1) self-identification as Black/African American;2) aged 15 to 29 years; 3) attending the clinic to be tested for HIV or other STIs, 4) the ability to speak and comprehend English, and 5) engaging in penile-anal sex, as an insertive partner with a male, at least once in the past 6 months (this criterion was needed for the larger study, as that 


\section{ACCEPTED MANUSCRIPT}

randomized controlled trial was designed to test an intervention for men using condoms as the insertive partner).

Age-eligible Black males were approached in clinic waiting areas and asked about their interest in volunteering for an HIV prevention study. Those expressing interest were screened for eligibility. Of 871 men screened, 621 were eligible. Those screening eligible were offered the opportunity to enroll in the study. After being offered the opportunity to enroll, 21 YBMSM declined, yielding a participation rate of $96.5 \%$. All study procedures were approved by the Institutional Review Board at the [Blinded for Review] and the Office of Research Integrity at the [Blinded for Review].

\section{$\underline{\text { Assessment }}$}

Men completed an online questionnaire, using Qualtrics software, in a private office not physically connected to the clinic. All sexual behaviors were assessed using a 90-day recall period. Two key items in this Qualtrics interview were: 1) In the past 90 days, how many times have you had oral sex (blow jobs) with a male partner (mouth to penis)? 2) Of the number of times you had oral sex (blow jobs) in the past 90 days (the number you just entered), how many times were condoms used? The data collected from the latter item was subtracted from the former item to create a measure of recent unprotected oral sex. Of note, we specifically used the term "blow job" as a method of separating oral-genital sex from oral-anal sex.

Social cognitive theory (SCT) provided a framework for variable selection. ${ }^{11}$ Antecedents were selected based on the premise that condom-related attitudes and experiences would be the most likely antecedents of condom-protected sex. Experiences were all measured using a recall 


\section{ACCEPTED MANUSCRIPT}

period of the past 90 days. Based on the concept of outcome expectations from SCT, five questions assessed men's attitudes regarding the influence of condoms on various aspects of sexual pleasure. Based on the SCT construct of self-efficacy, one question assessed men's level of perceived difficulty applying condoms. Also, based on the SCT premise that related behaviors tend to occur with equal frequency, we assessed whether men had recently engaged in condomless anal insertive sex and whether they had recently engaged in condomless anal receptive sex. Further, based on the SCT premise that the immediate environment influences behavior, three questions assessed men's sexual partnership behaviors (i.e., sex with females, sex with strangers, and oral sex with multiple partners). Finally, based on the SCT construct of anticipatory behaviors, one question assessed whether men always discussed condom use before sexual arousal and another assessed whether men always brought condoms to locations where sex occurred. These thirteen antecedents are displayed in Table 1.

Subsequent to completing the online questionnaire, men were evaluated for Chlamydia and gonorrhea in three anatomic locations; urethral and rectal infections were detected through nucleic acid amplification testing (NAAT) performed on a rectal swab; oral infections were detected through NAAT testing of a buccal swab. In addition a blood sample was collected to test for HIV (for those not already HIV-positive by clinic record) by use of OraSure.

\section{$\underline{\text { Data Analysis }}$}

Bivariate associations between the twelve antecedents and condom-protected oral sex were tested using chi-squared analyses. Antecedents significantly associated with the outcome were then entered into a multiple logistic regression model using Forward Wald Entry (a stepwise 


\section{ACCEPTED MANUSCRIPT}

procedure). Significance was defined by an alpha level of $\leq .05$. Data were analyzed using SPSS (version 22.0).

\section{Results}

Average age of the men was 22.6 years $(s d=3.21)$. Men's average monthly income ranged from less than $\$ 500$ per month (19.0\%), to $\$ 500-\$ 1,000$ per month (25.4\%), to $\$ 1,001$ $\$ 1,500$ (18.6\%), to $\$ 1,501-\$ 2,000(17.2 \%)$, to greater than $\$ 2,000$ (19.8\%). More than one-half (66.2\%) reported having education beyond high school graduation and $48.7 \%$ reported current enrollment in a school or college. The number of male anal sex partners (lifetime) reported ranged from 1-1000, with a median of 8 , a mean of $25.8(s d=81.5)$. In the past 90 days, the mean number of male sex partners when the enrolled men were the insertive partners in anal sex was $2.65(s d=7.6)$ and the mean number of male sex partners when the enrolled men were receptive partners in anal sex was $2.29(s d=4.4)$. More than one-fifth $(22.1 \%)$ tested positive for Chlamydia and one-fifth tested positive for gonorrhea (20.6\%). Nearly one-quarter (22.8\%) were HIV-positive at study enrollment. Pharyngeal Chlamydia was diagnosed in $4.6 \%$ of the men and Pharyngeal gonorrhea was diagnosed in $10.0 \%$ of the men.

Of the 609 men enrolled in the study, $526(86.4 \%)$ reported having oral sex in the past 90 days. Of these $\mathbf{5 2 6}$ men, the mean number of times they had oral sex was $9.45(s d=15.10)$. The mean number of times condoms were used for oral sex was .60 $(s d=1.99)$. Ninety-seven (18.4\%) reported that oral sex was always protected by condoms. The obtained distribution of unprotected oral sex frequency ranged from 0 to 115 times. The mean was 7.21 times $(s d=$ 13.97) and the distribution had an extreme positive skew (skewness ratio $=48.1$ ). 


\section{ACCEPTED MANUSCRIPT}

\section{$\underline{\text { Bivariate Associations }}$}

Table 1 presents the findings from the chi-square tests of associations. As shown, eleven of the thirteen antecedents had significant associations with condom-protected oral sex. All five of the items assessing sexual pleasure associated with condom use were significantly related to the outcome. In each case, men with favorable pleasure-associated attitudes toward condom use were more likely to always use condoms for oral sex. Also, the two measures pertaining to men's consistent condom use for anal sex (as an insertive partners and as a receptive partner) were significantly associated with the outcome. In both cases men always using condoms for anal sex were more likely to always use condoms for oral sex. Also, men who reported having sex with women were more likely to have condom-protected oral sex. Further, men having oral sex with only one partner in the past 90 days were more likely to report always using condoms for oral sex. Finally, men indicating that they always discussed condom use with male partners before becoming sexually aroused and men who took condoms with them when seeking sex were more likely to have condom-protected oral sex.

\section{$\underline{\text { Multivariate Associations }}$}

Before constructing the multivariate model, we tested two associations that may have been potential sources of confounding. Age was tested for association with condom-protected oral sex by use of a $t$-test. The mean age did not differ between men always using condoms for oral sex and those having unprotected oral sex $(P=.63)$. Also, a chi-square test was used to detect a possible association with HIV status. Of those who were HIV-negative $(n=406) 18.2 \%$ reported always using condoms for oral sex compared with $19.2 \% \%$ of those who were HIV-positive $(\mathrm{n}=$ 


\section{ACCEPTED MANUSCRIPT}

$120)$; this difference was not significant $(P=.82)$. Thus, the model was constructed with only the ten antecedents testing significant at the bivariate level.

The model fit was excellent (model $\chi^{2}=43.5, d f=3, p<.001$ ) as was the Goodness of Fit index $\left(\chi^{2}=3.00, d f=5, p=.70\right)$. Only three of the antecedents retained significance in the multivariate model. Men who had engaged in any unprotected anal sex as a receptive partner were about $69 \%$ less likely to report always using condoms for oral sex compared to their counterparts always using condoms for receptive anal sex (adjusted odds ratio $=.31,95 \% \mathrm{CI}=.13-.72 ; p=.007$ ). Men agreeing that "Condoms help me enjoy sex" were more than 2.5 times as likely to always use condoms for oral sex that their counterparts not endorsing the idea of condoms helping them to enjoy sex (adjusted odds ratio $=2.54,95 \% \mathrm{CI}=1.35-4.78 ; p=.004$ ). Also, men indicating that they always discussed condom use before arousal were more than 2.5 times as likely to always use condoms for oral sex that their counterparts not making this same indication (adjusted odds ratio $=2.54,95 \% \mathrm{CI}=1.41-4.61 ; p=.002)$.

\section{Discussion}

In this clinic-based sample of young Black MSM residing in a high HIV seroprevalence city of the southern U.S., about one of every five of those recently engaging in oral sex reported always using condoms. This prevalence of condom use for oral sex exceeds that reported in studies of undergraduate students $(4.9 \%),{ }^{12}$ heterosexual men and women from the National Survey of Family Growth $(6.4 \% \text { and } 5.7 \%)^{13}$ youth recruited from STI clinics (less than 5\%) $)^{13}$ and other populations of MSM..$^{7-9}$ The primary antecedents of always using condoms for oral sex in the current study were: 1) always using condoms for anal receptive sex, 2) agreement with the 


\section{ACCEPTED MANUSCRIPT}

statement that, "Condoms help me enjoy sex," and 3) always discussing condom use with partners before sexual arousal.

That consistent condom use for receptive anal sex, as opposed to insertive anal sex, retained multivariate significance in predicting condom use for oral sex suggests that some men may be quite vigilant with insisting that condoms be used and perhaps quite successful in being sure that their top partner or insertive oral sex partner uses condoms. Factors that contribute to the motivation and skill of these men relative to their vigilance in condom use require further investigation.

Men endorsing the concept of condoms helping them to enjoy sex were about 2.5 times as likely to use condoms consistently for oral sex, strongly suggesting that pleasure-related aspects of condom use are indeed vital antecedents that may have great value as targets of behavioral intervention programs. This measure ("condom help me enjoy sex") was global; it was not assessed specifically for protected anal or oral sex. Endorsement of the measure may signify that men generally feel less inhibited about sex and ejaculation because they are secure in the idea of being protected against the acquisition or transmission of oral pathogens (e.g., Chlamydia, gonorrhea, human Papillomavirus) and possibly HIV. Elimination of these "fear factors" may lead to increased dominance of excitation factors thereby intensifying the experience of orgasm. Similarly, beliefs about condom use making men feel more relaxed were associated with intention to use condoms among MSM in New York city. ${ }^{6}$ Also in this New York city study, beliefs that condom use decreases sensation were associated with lower intentions to use condom use. ${ }^{6}$ A focus on sensation and orgasm, as well as the relaxation that 


\section{ACCEPTED MANUSCRIPT}

can occur when using condoms as a result of decreased anxiety, may prove useful in sex-positive safer sex programs. Of note, the belief that condoms add to the enjoyment of sex retained multivariate significance rather than the variable representing endorsement of "Condoms intensify orgasm." This suggests that the specific focus on orgasm was less important than the general concept of "better sex." In 2001, Levina and colleagues suggested that it may be difficult to convince MSM that condom use for oral sex will not decrease their sexual sensation. ${ }^{6}$ Nearly fifteen years later, it appears that the norms among YBMSM in a high HIV/STI seroprevalence community may have possibly shifted.

The third significant multivariable finding is also intriguing. The finding that men who always discussed condom use with their male partners before sexual arousal was associated with greater odds of always using condoms for oral sex suggests the value of emphasizing to men that condom negotiation should occur before "passions flare." From an intervention perspective, the finding suggests that teaching YBMSM the value of these pre-sex discussions (as well how to engage partners in these discussions) could potentially be beneficial.

Because multivariate models may mask important antecedents, some of the significant bivariate findings warrant consideration. For instance, it is noteworthy that men having female sex partners were more likely to practice consistent condom use for oral sex; whether this is motivated by desire to protect female partners from infections that may stem from other men is a valid question for further research. Also, that men with only one oral sex partner were more

likely to always use condoms for oral sex suggests the possibility that YBMSM may find it difficult to discuss/negotiate condom use for oral sex with multiple partners. 


\section{ACCEPTED MANUSCRIPT}

The findings pertaining to always discussing condom use before sex and to the perception that condoms add to the enjoyment of sex each provide direction that can inform behavioral interventions designed to promote the behavior of condom-protected oral sex among YBMSM. Further, that men reporting recent condomless anal receptive sex were less likely to use condoms for oral sex suggests that behavioral interventions should target both behaviors. Finally, it is noteworthy that MSM may be able and willing to use condoms correctly for oral sex. For example, one study found a lower condom failure rate during oral sex than anal sex, ${ }^{9}$ thus suggesting that condom-protected oral sex could be a safer substitute for protected anal sex.

\section{$\underline{\text { Limitations }}$}

The single most important limitation is the lack of assessing whether men were insertive or receptive partners in oral sex. Further, whether ejaculation occurred in the oral cavity was not assessed. For men who were insertive in oral sex, the endorsement of condoms intensifying orgasm makes sense; however, the same cannot be said for men who were primarily receptive partners in oral sex. Thus, the study can only fairly conclude the endorsement of condoms intensifying orgasm signals a positive overall view of condoms and this view is an antecedent of condom-protected oral sex. Stated differently, the absence of oral sex-specific assessment of variables related to pleasure is a study limitation. Similarly, we did not assess oral sex-specific perceptions of risk or severity relative to orally-acquired STIs. Limitations also include the use of a convenience sample that was recruited for participation in randomized trial of 12-months in duration. 


\section{ACCEPTED MANUSCRIPT}

\section{$\underline{\text { Conclusion }}$}

Evidence from this clinic-based sample of YBMSM suggests that as many as one of every five or six YBMSM attending STI clinics may always be using condoms for oral sex with other men. This is an encouraging indication that safer sex behaviors may be extending to oral sex. In an era of increasing awareness that oral HPV may predispose to head and neck cancers ${ }^{14,15}$ and increasing incidence of pharyngeal infections with Chlamydia and gonorrhea, ${ }^{16}$ behavioral interventions designed to further increase the number of YBMSM always using condoms for oral sex may be warranted. "Although more definitive investigations are warranted, the findings from this study suggest the possibility that these interventions may especially benefit men by a focus on the sex-positive aspects of condom use particularly the role condoms may have regarding "better sex."

Funding

National Institute of Mental Health, Grant ID: R01MH092226 


\section{ACCEPTED MANUSCRIPT}

\section{References}

1. Centers for Disease Control and Prevention. Monitoring selected national HIV prevention and care objectives by using HIV surveillance data-United States and 6 dependent areas-2012. HIV Surveillance Supplemental Report 2014;19(No.3). Published November 2014.

2. Black AIDS Institute. Back of the line: The state of AIDS among Black gay men in America 2012. Available at:

http://www.Blackaids.org/index.php?option=com_content \&view=article \&id=1284\&Item $\mathrm{id}=198$.

3. Baggaley RF, White RG, Boily M-C. Systematic review of orogenital HIV-1 transmission probabilities. Int J Epidemiol. 2008 Dec; 37: 1255-1265.

4. Transmission of Primary and Secondary Syphilis by Oral Sex --- Chicago, Illinois, 1998-2002. Morbidity and Mortality Weekly Report, 2004; 53(41) http://www.cdc.gov/mmwr/preview/mmwrhtml/mm5341a2.htm

5. CDC. Primary HIV infection associated with oral transmission. Rockville, MD: CDC National Prevention Information Network, 2000.

6. Levina M, Danta, G, Fishbein M, et al. Factors influencing MSMs intentions to always use condoms for vaginal, anal, and oral sex with their regular partners. Psychol Health Med 2001; 6: 191-206. 


\section{ACCEPTED MANUSCRIPT}

7. Koh KC, Kanagalingam K, Tai FT, et al. Sexual practices and HIV prevalence amongst men who have sex with men at a community-based voluntary counseling and testing centre in Malaysia. ISRN Infect Dis 2013, http://dx.doi.org/10.5402/2013/247545

8. Zou H, Wu Z, Yu et al. Sexual risk behaviors and HIV infection among men who have sex with men who use the internet in Beijing and Urumqi, China. 2010; J Acquir Immune Defic Syndr. 2010; 53: Suppl 1:S81-7 10.1097/QAI.0b013e3181c7dd2b

9. Thompson JLP, Yager TJ, Martin JL. Estimated condom failure and frequency of condom use among gay men. Am J Pub Health 1993; 83: 1409-1413.

10. Transmission of Primary and Secondary Syphilis by Oral Sex --- Chicago, Illinois, 1998-2002. Morbidity and Mortality Weekly Report, 2004; 53(41) http://www.cdc.gov/mmwr/preview/mmwrhtml/mm5341a2.htm

11. Crosby RA, DiClemente RJ, Salazar LF. Social Cognitive Theory applied to health behavior. In DiClemente, R. J., Crosby, R. A., \& Salazar, L. F. (eds) Understanding and Changing Health Behavior: A Theory-Based Multidisciplinary Approach. Burlington, MA: Jones \& Bartlett Learning, 2013.

12. Gurman T, Borzekowski DL. Condom use among Latino college students. J Am Coll Health 2004; 52: 169-178.

13. Leichliter JS, Chandra A, Liddon N, et al. Prevalence and Correlates of Heterosexual Anal and Oral Sex in Adolescents and Adults in the United States. J Infect Dis 2007; 196: 1852-1859. 


\section{ACCEPTED MANUSCRIPT}

14. Fridlund V, Stenqvist K, Nordvik MK. Condom use: The discrepancy between practice and behavioral expectations. Scand J Pub Health 2014; 42: 759-765.

15. Syrjanen S. The role of human papillomavirus infection in head and neck cancers. Annals Oncol 2010; 21: vii243-vii245

16. Tahwinder U, Jerjes W, Al-Khawalde M. Oral sex, cancer and death: Sexually transmitted cancers. Head Neck Oncol 2012; 31: doi:10.1186/1758-3284-4-31

17. Weinstock H, Workowaki, KA. Pharyngeal Gonorrhea: An Important Reservoir of Infection? Clin Infect Dis 2009; 49: 1798-1800. 


\section{ACCEPTED MANUSCRIPT}

Table 1. Bivariate Associations Between Selected Antecedents and Condom-Protected Oral Sex Among 526 Young Black MSM

\begin{tabular}{|c|c|c|}
\hline$\underline{\text { Antecedent }}$ & $\begin{array}{l}\text { \% Always }{ }^{1} \text { Using Condoms for Oral } \\
\underline{\text { Sex }}\end{array}$ & $\underline{p}^{2}$ \\
\hline \multicolumn{3}{|c|}{ "Condoms help me enjoy anal sex" } \\
\hline No & $11.2(31 / 247)$ & \\
\hline Yes & $26.6(66 / 248)$ & $<.001$ \\
\hline \multicolumn{3}{|c|}{ "Condoms help me intensify orgasm" } \\
\hline No & $13.0(50 / 334)$ & \\
\hline Yes & $33.1(47 / 95)$ & $<.001$ \\
\hline \multicolumn{3}{|c|}{ "Condoms help me have better sex" } \\
\hline No & $11.6(32 / 277)$ & \\
\hline Yes & $26.1(65 / 249)$ & $<.001$ \\
\hline \multicolumn{3}{|c|}{ Feel closer to partner without condoms } \\
\hline No & $20.4(86 / 421)$ & \\
\hline Yes & $10.5(11 / 105)$ & .02 \\
\hline \multicolumn{3}{|c|}{ "Condom feel unnatural" } \\
\hline No & $20.4(89 / 437)$ & \\
\hline Yes & $9.0(8 / 89)$ & .012 \\
\hline \multicolumn{3}{|c|}{ Recent difficulty applying condoms ${ }^{3}$} \\
\hline No & $16.6(55 / 231)$ & \\
\hline Yes & $21.5(42 / 195)$ & .16 \\
\hline
\end{tabular}




\section{ACCEPTED MANUSCRIPT}

\begin{tabular}{|c|c|c|}
\hline \multicolumn{3}{|c|}{ Any recent unprotected anal insertive sex ${ }^{4}$} \\
\hline No & $22.7(77 / 339)$ & \\
\hline Yes & $5.1(7 / 137)$ & $<.001$ \\
\hline \multicolumn{3}{|c|}{ Any recent unprotected anal receptive $\operatorname{sex}^{5}$} \\
\hline No & $24.6(62 / 252)$ & \\
\hline Yes & $8.5(12 / 130)$ & $<.001$ \\
\hline \multicolumn{3}{|c|}{ Recent sex with females } \\
\hline No & $16.4(71 / 434)$ & \\
\hline Yes & $28.3(26 / 92)$ & .008 \\
\hline \multicolumn{3}{|c|}{ Recent sex with a stranger } \\
\hline No & $19.0(71 / 374)$ & \\
\hline Yes & $17.1(26 / 152)$ & .61 \\
\hline \multicolumn{3}{|c|}{$\begin{array}{l}\text { More than one male oral sex partner } \\
\text { (past } 90 \text { days) }\end{array}$} \\
\hline No & $23.0(48 / 209)$ & \\
\hline Yes & $15.5(49 / 317)$ & .03 \\
\hline \multicolumn{3}{|c|}{ Always discuss condom use before arousal ${ }^{2}$} \\
\hline No & $13.7(50 / 365)$ & \\
\hline Yes & $29.2(47 / 161)$ & $<.001$ \\
\hline \multicolumn{3}{|c|}{ Always bring condoms when seeking sex } \\
\hline No & $11.9(26 / 192)$ & \\
\hline Yes & $23.1(71 / 308)$ & .001 \\
\hline
\end{tabular}




\section{ACCEPTED MANUSCRIPT}

1“"Always" includes men indicating "always" and "almost always"

${ }^{2} \mathrm{P}$-values pertain to chi-squared tests

${ }^{3}$ Among 426 reporting they had used condoms as an insertive partner in the past 90 days

${ }^{4}$ Among 476 reporting they had engaged in anal insertive sex in the past 90 days

${ }^{5}$ Among 382 reporting they had engaged in anal receptive insertive sex in the past 90 days 